\title{
Prognostic impact of p53 aberrations for R-CHOP- treated patients with diffuse large B-cell lymphoma
}

\author{
LENKA STEFANCIKOVA $^{1,2}$, MOJMIR MOULIS ${ }^{1}$, PAVEL FABIAN $^{3}$, INGRID VASOVA $^{4}$, FRANTISEK ZEDEK $^{2}$, \\ BARBORA RAVCUKOVA $^{5}$, JAN MUZIK ${ }^{6}$, PETR KUGLIK ${ }^{2,7}$, VLADIMIRA VRANOVA ${ }^{2,7}$, IVA FALKOVA ${ }^{1}$, \\ RENATA HRABALKOVA $^{1}$ and JANA SMARDOVA ${ }^{1,2}$
}

\begin{abstract}
Departments of ${ }^{1}$ Pathology and ${ }^{4}$ Hematooncology, University Hospital Brno, Jihlavska 20, 62500 Brno; ${ }^{2}$ Department of Experimental Biology, Faculty of Sciences, Masaryk University, Kotlarska 2, 61137 Brno; ${ }^{3}$ Department of Pathology, Masaryk Memorial Cancer Institute, Zluty kopec 7, 65653 Brno; ${ }^{5}$ Molecular Genetics Laboratory, Centre for Cardiovascular Surgery and Transplantation, Vystavni 17/19, 60300 Brno; ${ }^{6}$ Institute of Biostatistics and Analyses, Masaryk University, Komenskeho namesti 2, 66243 Brno; ${ }^{7}$ Department of Medical Genetics, University Hospital, Cernopolni 9, 61300 Brno, Czech Republic
\end{abstract}

Received June 7, 2011; Accepted July 11, 2011

DOI: $10.3892 /$ ijo.2011.1170

\begin{abstract}
Diffuse large B-cell lymphoma (DLBCL) is the most frequent lymphoma in adults. There are specific alterations that appear repeatedly in DLBCL cases and play a role in lymphomagenesis or progression of the disease. Some aberrations were used as prognostic markers in the pre-rituximab era. Addition of rituximab to the classical anthracycline-based chemotherapy significantly increased the survival rate in DLBCL. Only few prognostic factors have been re-evaluated for patients treated with R-CHOP (rituximab, cyclophosphamide, doxorubicin, vincristine and prednisone). We performed complex analysis of the p53 tumor suppressor in collection of 75 DLBCL cases. Fifty-four patients were de novo cases, twenty-one cases developed into DLBCL by transformation from less aggressive disease. We determined functional status by analysis of separated alleles in yeast (FASAY) and analyzed the $p 53$ mutations by cDNA sequencing. We assessed the level of the p53 protein by immunoblot analysis. We used FISH to analyze loss of the p53 and ATM (ataxia telangiectasia mutated) gene deletions. We detected 16 p53 mutations $(21.3 \%)$ including the mutation activating non-sense-mediated RNA decay pathway. Deletion of the p53 allele was more common in cases with $p 53$ mutation. Mutations and/or deletions of $p 53$ had statistically significant negative impact on progression-free survival and tended to decrease also overall survival in 46 de novo DLBCL patients treated with R-CHOP. p53 aberrations are negative predictors for survival of DLBCL patients treated with R-CHOP.
\end{abstract}

Correspondence to: Dr Jana Smardova, Department of Pathology, University Hospital, Jihlavska 20, 62500 Brno, Czech Republic E-mail: janasmarda@seznam.cz

Key words: diffuse large B-cell lymphoma, tumor suppressor p53, functional status by analysis of separated alleles in yeast, overall survival, progression free survival

\section{Introduction}

Diffuse large B cell lymphoma (DLBCL) is the most frequent lymphoma in adults. The tumor is characterized by centroblastlike and immunoblast-like cells expressing typical B-cell markers (CD19, CD20, CD22, CD79a) and the surface immunoglobulin (sIg). The DLBCLs vary in morphology, immunophenotype and clinical features $(1,2)$. Gene expression profiling identified three distinct subgroups of DLBCL: germinal center B-celllike (GCB), activated B-cell-like (ABC) and primary mediastinal (PM) DLBCL (3-7). The subgroups are derived from different cell of origin and arise by distinct genetic pathways (8). Several algorithms have been proposed to stratify DLBCL cases into GCB and non-GCB (ABC) subgroups according to the immunophenotype (9-12). These immunohistochemically defined subgroups differ in clinical outcome when treated with anthracycline-based chemotherapy (CHOP) $(13,14)$, but this divergence is eliminated by addition of rituximab (14), chimeric monoclonal antibody binding to CD20 and activating apoptosis of CD20positive cells (15). Addition of rituximab has significantly improved survival of DLBCL patients $(16,17)$.

DLBCL is characterized by highly heterogeneous genetic and cytogenetic aberrations (18). Some alterations appear repeatedly in DLBCL cases probably playing a role in lymphomagenesis or progression of the disease. These include rearrangements involving bcl-2, c-myc (2) and bcl-6 (19), pl6INK4A inactivation and p53 mutation (20). The adverse impact of $b c l-6$ and $b c l-2$, was overcome by rituximab supplement $(21,22)$.

Alterations of $p 53$ represent the most common genetic defect occurring in about half of all malignancies. In DLBCL, the p53 mutations are detected in $13-22 \%$ of cases. Its association with worsened OS and PFS was described for DLBCL treated with chemotherapy alone (23-28).

p53 is a stress-responding tumor suppressor participating in control of the cell cycle, DNA repair, apoptosis and senescence $(29,30)$. Inactivation of p53 increases cell proliferation and survival and promotes genomic instability and chemotherapy resistance of tumors (31). Inactivation of p53 usually results 
from missense mutations in core region of the $p 53$ gene coding for the sequence-specific DNA-binding domain. The remaining p53 allele can be inactivated by deletion, but some mutant p53 exert dominant-negative effect thus inactivating the wild-type p53 protein. The resulting mutated $\mathrm{p} 53$ protein might gain new oncogenic properties (32). Due to the inability to transactivate its negative regulator, the E3-ubiquitin ligase MDM2 (33-35), mutant $\mathrm{p} 53$ protein often accumulates in tumor cells.

Upstream of the p53 acts the serine/threonine kinase ATM responding to double-strand breaks in DNA (36). The p53 and ATM pathways overlap but they are not consistent in suppression of tumorigenesis. Combined status of both p53 and ATM could be an important determinant of the malignant phenotype $(37,38)$. The ATM deletion shortened survival of patients with DLBCL (39). Other studies, however, did not find any association of the ATM deletion with prognosis of lymphoma patients (40-42).

We present results of complex analysis of the p53 tumor suppressor in 75 DLBCL cases. We determined the p53 status by FASAY and analyzed the $p 53$ mutations by cDNA sequencing. We assessed the p53 protein level by immunoblot analysis and used FISH to determine the loss of the p53 gene. We used FISH also to study the ATM deletion. We statistically evaluated the role of $p 53$ aberrations in subset of de novo DLBCL patients treated with R-CHOP.

\section{Materials and methods}

Samples and patients. Seventy-five patients diagnosed with DLBCL (34 females and 41 males) underwent surgical biopsy of the tumor tissue in University Hospital in Brno from 2001 to 2009. Diagnosis of DLBCL was assessed by two experienced pathologists according to the WHO classification. Twenty-one patients developed DLBCL as a secondary tumor transformed either from follicular lymphoma ( 7 cases), chronic lymphocytic leukemia/small lymphocytic lymphoma (5 cases), marginal zone lymphoma (4 cases), low grade lymphoma not otherwise specified ( 3 cases) or nodular lymphocyte predominant Hodgkin lymphoma ( 2 cases).

For all patients, fresh-frozen tissue samples as well as formalin-fixed, paraffin-embedded (FFPE) tumor tissue blocks were available. Among primary DLBCL, in 12 cases, the analyzed material was obtained at the time of relapse. GC and non-GC subtypes were distinguished based on the algorithm of Hans et al (9). Clinical information was available for all cases. The characteristics of the patients with respect to sex, age, stage, International prognostic index (IPI) and treatment are listed in Table I. All patients provided informed consent.

FASAY and split assay. FASAY was performed as described earlier $(43,44)$. Total RNA was purified using RNeasy mini kit (Qiagen Inc., Valencia, CA, USA). cDNA was synthesized by SuperScript II (Life Technologies Inc., Carlsbad, CA, USA) using primer oligo $(\mathrm{dT})_{12}$. PCR was performed using primers P3 (5'-CCT-TGC-CGT-CCC-AAG-CAA-TGG-ATG-AT-3'), P4 (5'-ACC-CTT-TTT-GGA-CTT-CAG-GTG-GCT-GGAGT-3'), and $P f u$ DNA polymerase (Stratagene, La Jolla, CA, USA). Yeast cells were co-transformed with the PCR product, linearized pSS16 plasmid, and the salmon sperm DNA carrier (Life Technologies) by the lithium acetate procedure (45).
Table I. Clinicopathological data of analyzed samples.

\begin{tabular}{|c|c|c|c|}
\hline & $\begin{array}{c}\text { De novo } \\
\mathrm{N}=54(\%)\end{array}$ & $\begin{array}{l}\text { Transformations } \\
\qquad \mathrm{N}=21(\%)\end{array}$ & $\begin{array}{c}\text { All } N=75 \\
(\%)\end{array}$ \\
\hline \multicolumn{4}{|l|}{ Gender } \\
\hline Male & $31(57.4)$ & $10(47.6)$ & $41(54.7)$ \\
\hline Female & $23(42.6)$ & $11(52.4)$ & $34(45.3)$ \\
\hline \multicolumn{4}{|l|}{ Age (years) } \\
\hline Average & 53 & 51 & 52 \\
\hline Median & 57 & 54 & 54 \\
\hline Range & $20-85$ & $16-65$ & $16-85$ \\
\hline \multicolumn{4}{|l|}{ Distribution $^{\mathrm{a}}$} \\
\hline GCB & $20(37.0)$ & $11(52.4)$ & $31(41.3)$ \\
\hline Non-GCB & $34(63.0)$ & $10(47.6)$ & $44(58.7)$ \\
\hline \multicolumn{4}{|l|}{ Stage } \\
\hline I & $4(7.4)$ & & $4(5.3)$ \\
\hline II & $14(25.9)$ & $1(4.8)$ & $15(20.0)$ \\
\hline III & $12(22.2)$ & $3(14.3)$ & $15(20.0)$ \\
\hline IV & $24(44.4)$ & $11(52.4)$ & 35 (46.7) \\
\hline Unknown & & $6(28.6)$ & $6(8.0)$ \\
\hline \multicolumn{4}{|l|}{ IPI } \\
\hline 0 & $6(11.1)$ & & $6(8.0)$ \\
\hline 1 & $10(18.5)$ & $2(9.5)$ & $12(16.0)$ \\
\hline 2 & $8(14.8)$ & $5(23.8)$ & $13(17.3)$ \\
\hline 3 & $17(31.5)$ & $5(23.8)$ & $22(29.3)$ \\
\hline 4 & $12(22.2)$ & $1(4.8)$ & 13 (17.3) \\
\hline 5 & $1(1.9)$ & & $1(1.3)$ \\
\hline Unknown & & $8(38.1)$ & $8(10.7)$ \\
\hline \multicolumn{4}{|l|}{ IPI AA } \\
\hline 0 & $7(13.0)$ & & $7(9.3)$ \\
\hline 1 & $11(20.4)$ & $4(19.0)$ & $15(20.0)$ \\
\hline 2 & $17(31.5)$ & $8(38.1)$ & $25(33.3)$ \\
\hline 3 & $19(35.2)$ & $1(4.8)$ & $20(26.7)$ \\
\hline Unknown & & $8(38.1)$ & $8(10.7)$ \\
\hline \multicolumn{4}{|l|}{ ECOG } \\
\hline 0 & $16(29.6)$ & $3(14.3)$ & $19(25.3)$ \\
\hline 1 & $15(27.8)$ & $9(42.9)$ & $24(32.0)$ \\
\hline 2 & $16(29.6)$ & $1(4.8)$ & 17 (22.7) \\
\hline 3 & $6(11.1)$ & & $6(8.0)$ \\
\hline 4 & $1(1.9)$ & & $1(1.3)$ \\
\hline Unknown & & $8(38.1)$ & $8(10.7)$ \\
\hline \multicolumn{4}{|l|}{ Primary therapy } \\
\hline Standard & $38(70.4)$ & $9(42.9)$ & $47(62.7)$ \\
\hline Intensive & $14(25.9)$ & $2(9.5)$ & $16(21.3)$ \\
\hline No/unknown & $2(3.7)$ & $10(47.6)$ & $12(16.0)$ \\
\hline \multicolumn{4}{|l|}{ PT response } \\
\hline $\mathrm{CR}$ & $47(87.0)$ & $12(57.1)$ & $59(78.7)$ \\
\hline PR & $2(3.7)$ & $1(4.8)$ & $3(4.0)$ \\
\hline Prog & $2(3.7)$ & $1(4.8)$ & $3(4.0)$ \\
\hline Unknown & $3(5.6)$ & $7(33.3)$ & $10(13.3)$ \\
\hline
\end{tabular}

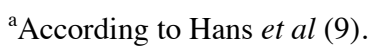

Transformed yeast cells were plated on minimal medium lacking leucine and with $5 \mu \mathrm{g} / \mathrm{ml}$ of adenine, followed by 
incubation at $35^{\circ} \mathrm{C}$ for 2-3 days, and then for 2-3 days at room temperature. For split assay, PCR of the p53 5'-part was performed with primers P3 and P17 (5'-GCC-GCC-CATGCA-GGA-ACT-GTTACA-CAT-3'), the 3'-part with primers P4 and P16 (5'-GCGATG-GTC-TGG-CCC-CTC-CTC-AGCATC-TTA-3'). Yeast cells were transformed with linearized vectors pFW35 and pFW34 (46).

FASAY deduces the functional status of p53 from color of colonies of transformed yeast cells. Expression of functional p53 results in large white colonies, inactive p53 leads to smaller red colonies. The background frequency of red yeast colonies typically does not exceed $10 \%$. Thus, samples providing $<10 \%$ of red colonies are considered to contain only wild-type $p 53$ alleles, while samples providing $>10 \%$ of red colonies are suspicious to bear a clonal p53 mutation (43). The ratio of red colonies scoring between 10 and $20 \%$ can result from a presence of clonal p53 mutation in rather small portion of cells or from increased degradation of RNA. To distinguish these two possibilities, version of FASAY, called split assay, was established. In the split assay, the 5'- and 3' parts of the $p 53$ cDNA are tested separately (46).

Purification of the plasmids from transformed yeast cells and sequencing of the p53 cDNA. Yeast cells from individual yeast colonies were harvested, resuspended in TSN (2\% Triton X-100, $1 \%$ SDS, $100 \mathrm{mM} \mathrm{NaCl}, 10 \mathrm{mM}$ Tris pH 8.0, 1 mM EDTA), and grinded by vortexing with glass beads; plasmid DNA was extracted by phenol/chloroform procedure. The $p 53$ cDNA was amplified using the P3 and P4 primers and Taq polymerase (Life Technologies) and subjected to agarose gel electrophoresis. The PCR product was purified by MinElute PCR purification kit (Qiagen) and sequenced by BigDye Terminator v3.1 cycle sequencing kit (Applied Biosystems, Darmstadt, Germany) using ABI PRISM 3100 Genetic Analyzer (Applied Biosystems).

Isolation of gDNA and amplification of exons 6 and 8 of p53. Genomic DNA was isolated from formalin-fixed, paraffin-embedded tissue blocks using the purogene DNA Isolation Kit (Gentra Systems, Minneapolis, MN, USA) according to the manufacturer's instructions. Exons 6 and 8 of the p53 gene were amplified by PCR using primers p53-Pg6Fa (5'-AGAGACGACAGGGCTGGTT-3'), p53-Pg6R (5'-CT TA ACCCCTCCTCCCAGAG-3', p53-Pg8Fb (5'-GCC-TCT-TGC-TTC-TCT-TTT-TCC-3'), p53-Pg8R (5'-TAA-CTG-CAC-CCT-TGG-TCT-CC-3') and Taq polymerase (Life Technologies). The PCR products were purified and sequenced as described above.

FISH. FISH was performed on tissue sections prepared from FFPE blocks. For the p53-specific locus analysis, the Vysis LSI TP53 (17p13.1) Spectrum Orange probe and the centromeric CEP 17 Spectrum Green DNA probe were used. For analysis of ATM locus, Vysis LSI ATM (11q22.3) Spectrum Orange probe and CEP 11 Alpha Spectrum Green DNA probe were used (Abbott Molecular Inc., Abbott Park, IL, USA). Hybridization was performed according to the manufacturer's instructions. Images were scanned by Leica DMRXA2 microscope equipped with CCD camera (COHU). Fluorescence signals were analyzed using Leica Q-FISH software (Leica
Microsystems GmbH, Wetzlar, Germany). Cells (50-100) per case were analyzed. The cut-off level was defined by the mean value plus three times the SD of the frequency of control cells exhibiting one red and two green signals $(9.6 \%$ for p53 and $9.8 \%$ for $A T M)$.

Array comparative genomic hybridization (CGH). Wholegenome analysis of chromosomal changes in case 44 was performed using oligonucleotide Human Genome CGH microarray 44K (Agilent Technologies, Santa Clara, CA, USA) according to the manufacturer's protocol. Briefly, $1 \mu \mathrm{g}$ of reference DNA (Promega Corp., Fitchburg, WI, USA) and test DNA were enzymatically restricted and labeled (Cy3-dUTP and Cy5-dUTP) using the random-priming reaction. Purified (Microcon YM-30 filters, Millipore), differentially labeled test and reference DNA were co-hybridized to the array containing about 43.000 short (60-mer) oligonucleotides representing both coding and non-coding sequences of whole human genome. After one day of hybridization, and washing off the unhybridized probes, microarrays were scanned with Agilent Microarray Scanner. Data were obtained using Feature Extraction software (v. 6.1.1) and visualized by CGH Analytics software (v. 3.5.14) (Agilent Technologies). Copy number changes were detected using ADM-2 algorithm with $\geq 3$ neighbouring oligos with significantly aberrant intensity ratios patient/reference.

Immunoblotting. Tissue samples were lysed in $150 \mathrm{mM} \mathrm{NaCl}$, $50 \mathrm{mM}$ NaF, $50 \mathrm{mM}$ Tris (pH 8.0), $5 \mathrm{mM}$ EDTA, 1\% NP40 and $1 \mathrm{mM}$ phenylmethylsulfonyl fluoride in ice for $30 \mathrm{~min}$, and the cell extract was centrifuged at $17,000 \mathrm{x}$ g for $30 \mathrm{~min}$ to remove cell debris. Protein concentration was measured by the Bradford assay. Solubilized proteins were resolved by $10 \%$ SDS-PAGE and transferred onto a nitrocellulose membrane. Blots were blocked in $0.1 \%$ Tween-20 and 5\% low-fat milk in PBS for $1 \mathrm{~h}$ and probed with anti-p53 mouse monoclonal antibody DO-1 (kindly provided by B. Vojtesek) at $4^{\circ} \mathrm{C}$. Blots were developed with Dako peroxidase-conjugated rabbit anti-mouse immunoglobulin (Dako, Glostrup, Denmark) using the ECL chemiluminescence detection kit (Amersham Biosciences, Vienna, Austria).

Statistical analyses. Frequency tables and descriptive statistics (mean, median, minimum and maximum) were used for summarizing characteristics of the patients. Differences between compared groups of patients were assessed by Maximum Likelihood Chi-square test and Fisher exact test in categorial variables and by Mann-Whitney test in continuous variables. Graphic visualization of patients' survival according to monitored parameters was performed using Kaplan-Meier survival curves. Differences in survival were tested using the log-rank test. As a level of statistical significance $\alpha=0.05$ was used. Analysis and graphic visualization were performed in statistical software SPSS 12.0.1 for Windows and Statistica 8.0 for Windows.

\section{Results}

Assessment of the p53 status by FASAY. We performed FASAY of all 75 samples (Table II). Fifty-eight cases scored under the background $10 \%$ level, 15 cases were positive and scored 
Table II. The cases with a p53 aberration.

\begin{tabular}{|c|c|c|c|c|}
\hline Case & FASAY\% $\%^{a}$ & p53 mutation & FISH \% ${ }^{b}$ & WB (DO-1) \\
\hline \multicolumn{5}{|c|}{ De novo DLBCL } \\
\hline 5 & 21.7 & $\mathrm{G} 244 \mathrm{~S}$ & 0.0 & - \\
\hline 8 & 12.1 & R196stop & 0.0 & - \\
\hline 51 & 80.3 & R248G & 0.0 & - \\
\hline 18 & 30.0 & $\mathrm{R} 273 \mathrm{H}$ & 0.0 & + \\
\hline 67 & 62.4 & del10nt 276-279 & 1.9 & $+^{\mathrm{c}}$ \\
\hline 7 & 96.8 & $\mathrm{G} 245 \mathrm{D}$ & 0.0 & +++ \\
\hline 73 & 74.1 & $\mathrm{R} 273 \mathrm{H}$ & 1.8 & +++ \\
\hline 47 & 46.3 & $\mathrm{R} 273 \mathrm{C}$ & 0.0 & +++ \\
\hline 35 & 32.0 & L257R & 4.7 & - \\
\hline 28 & 78.0 & C135R & 38.5 & + \\
\hline 30 & 73.6 & $\mathrm{I} 254 \mathrm{~N}$ & 29.5 & + \\
\hline 50 & 74.5 & $\mathrm{R} 175 \mathrm{H}$ & 53.6 & +++ \\
\hline 23 & 1.3 & - & 0.0 & +++ \\
\hline 60 & 5.0 & - & 0.0 & +++ \\
\hline 2 & 5.3 & - & 18.8 & - \\
\hline 43 & ND & ND & 29.5 & - \\
\hline \multicolumn{5}{|c|}{ Transformations } \\
\hline 3 & 70.0 & $\mathrm{C} 135 \mathrm{G}$ & 63.7 & +++ \\
\hline 4 & 94.0 & del 18nt 177-182 & 49.1 & +++ \\
\hline 44 & 83.4 & V272G & 50.0 & +++ \\
\hline 40 & 60.0 & $\mathrm{C} 238 \mathrm{~F}$ & 0.0 & +++ \\
\hline 53 & 7.5 & - & 50.8 & - \\
\hline 61 & 3.5 & - & 84.3 & + \\
\hline
\end{tabular}

a\% of red yeast colonies; ${ }^{\mathrm{b}} \%$ of cells with $p 53$ deletion; ${ }^{\text {ctruncated protein. }}$

above $20 \%$ of red colonies (ranged from 21.7 to $96.8 \%$ ). In case 8 , the result of FASAY was ambiguous as it scored $12.1 \%$. The split assay provided a rather symmetric result $(11.6 \%$ of red colonies for the 3'-part and $19.8 \%$ for the 5'-part of the p53 cDNA). From our previous analyses we know that this kind of result does not exclude the presence of a clonal p53 mutation. Therefore, this case was considered positive and further analyzed by cDNA and gDNA sequencing. We were not able to explicitly analyze case 43 , we repeatedly obtained only faint product of the p53 PCR and highly fluctuating results of FASAY.

Sequencing of the 553 cDNA. The 16 cases positive in FASAY/ split assay were analyzed further by cDNA sequencing. The p53 expression vector was recovered from 3 to 6 red colonies per case and the isolated cDNA was used as a template for sequencing. In all 16 cases, we detected clonal p53 mutations, i.e. the mutations were found in majority of analyzed colonies (Tables II and III). All detected p53 mutations were localized to the DNA-binding domain. Thirteen mutations $(81.3 \%)$ were missense. The non-sense mutation in case 8 formed premature termination codon in position 196. Mutations detected in cases 4 and 67 were recognized as deletions of
12 and 10 nucleotides, respectively. The deletion in case 67 resulted in the reading frame shift and formation of premature termination codon in position 345. We isolated gDNA from FFPE tissue of case 8 and sequenced exon 6 of the p53 gene (Fig. 1). We confirmed the presence of mutation R196 stop in the gDNA. The mutated $p 53$ allele represented majority in the sample contrary to results of FASAY showing presence of mutation in only rare colonies. This strongly suggests that the premature stop codon might activate the nonsense-mediated RNA decay pathway $(47,48)$.

Overall, a clonal p53 mutation was detected in 16 DLBCL cases $(21.3 \%), 12$ of them in de novo DLBCL cases. Two mutations (cases 35 and 47) were found in the tissue samples from disease relapse. We confirmed mutation R273C by sequencing of gDNA (exon 8) isolated from the primary biopsy FFPE block of case 47 . In case 35 , the quality of isolated gDNA was insufficient for DNA amplification.

The distribution of the detected p53 mutations was nonrandom. Six out of 13 missense mutations (46\%) affected 4 hot-spot codons (R175, G245, R248, R273), all 13 mutations spanned into evolutionary conserved regions, 6 were in region IV, 4 in region $\mathrm{V}, 2$ in region II and 1 in region III. Six mutations were in exon 7, 4 in exon 8 and 3 in exon 5 . 
Table III. Results of the p53 and ATM analyses.

\begin{tabular}{|c|c|c|c|}
\hline & $\begin{array}{c}\text { De novo } \\
\mathrm{N}=54(\%)\end{array}$ & $\begin{array}{c}\text { Transformations } \\
\mathrm{N}=21(\%)\end{array}$ & $\begin{array}{c}\text { All } \mathrm{N}=75 \\
(\%)\end{array}$ \\
\hline \multicolumn{4}{|c|}{ p53 mutation } \\
\hline Yes & $12(22.2)$ & $4(19.0)$ & $16(21.3)$ \\
\hline No & $42(77.8)$ & $17(81.0)$ & $59(78.7)$ \\
\hline \multicolumn{4}{|c|}{ p53 deletion } \\
\hline Yes & $5(9.3)$ & $5(23.8)$ & $10(13.3)$ \\
\hline No & 49 (90.7) & $16(76.2)$ & 65 (86.7) \\
\hline \multicolumn{4}{|c|}{$\begin{array}{l}\text { p53 mutation } \\
\text { and/or deletion }\end{array}$} \\
\hline Yes & $14(25.9)$ & $6(28.6)$ & $20(26.7)$ \\
\hline No & $40(74.1)$ & $15(71.4)$ & $55(73.3)$ \\
\hline \multicolumn{4}{|c|}{ p53 protein (WB) } \\
\hline- & $28(51.9)$ & $12(57.1)$ & $40(53.3)$ \\
\hline+ & $16(29.6)$ & $3(14.3)$ & $19(25.3)$ \\
\hline++ & $4(7.4)$ & $2(9.5)$ & $6(8.0)$ \\
\hline+++ & $6(11.1)$ & $4(19.0)$ & $10(13.3)$ \\
\hline \multicolumn{4}{|c|}{ ATM deletion } \\
\hline Yes & $6(11.1)$ & $4(19.0)$ & $10(13.3)$ \\
\hline No & $45(83.3)$ & $17(81.0)$ & $62(82.7)$ \\
\hline ND & $3(5.6)$ & & $3(4.0)$ \\
\hline
\end{tabular}

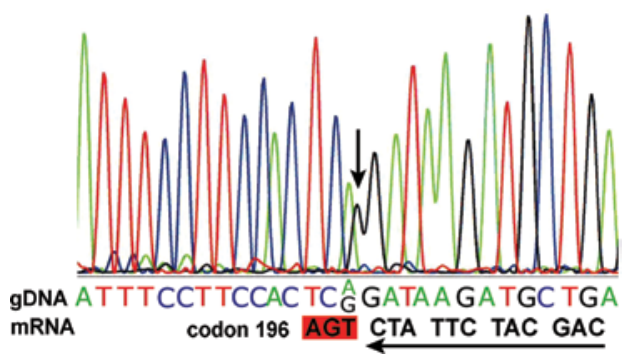

Figure 1. Result of the $p 53$ gDNA sequencing of case 8 . Arrow shows $\mathrm{G}$ to $\mathrm{A}$ substitution in the position 196 resulting in formation of premature termination codon.

Mutations C135G, I254N and V272G were temperature sensitive (49).

Detection of the 17p13.1 and 11q22.3 loci. We performed FISH analysis of both p53 and ATM alleles using the locus-specific (red) and centromeric (green) probes. In some cases, we found presence of only one red and one green signal per nucleus $(1 \mathrm{R}+1 \mathrm{G})$ in considerable high proportion of cells (Fig. 2). In case 44 , for instance, we detected $1 \mathrm{R}+1 \mathrm{G}$ pattern in $46.0 \%$ of nuclei when analyzing p53 and in $64.5 \%$ of nuclei when assessing ATM. To get deeper insight into the chromosome status in this case, we performed array-CGH analysis. We found long deletion overlapping centromeric region on both chromosome 17 (del 17p13.3-q21.2) and 11 (del 11p11.2-q25) (Fig. 2). This result clearly explained our observation by FISH. Nuclei containing one red and one green signal were considered as positive for $p 53 / A T M$ loss. Altogether, deletion of the p53 allele was found in 10 cases (Tables II and III). In six cases
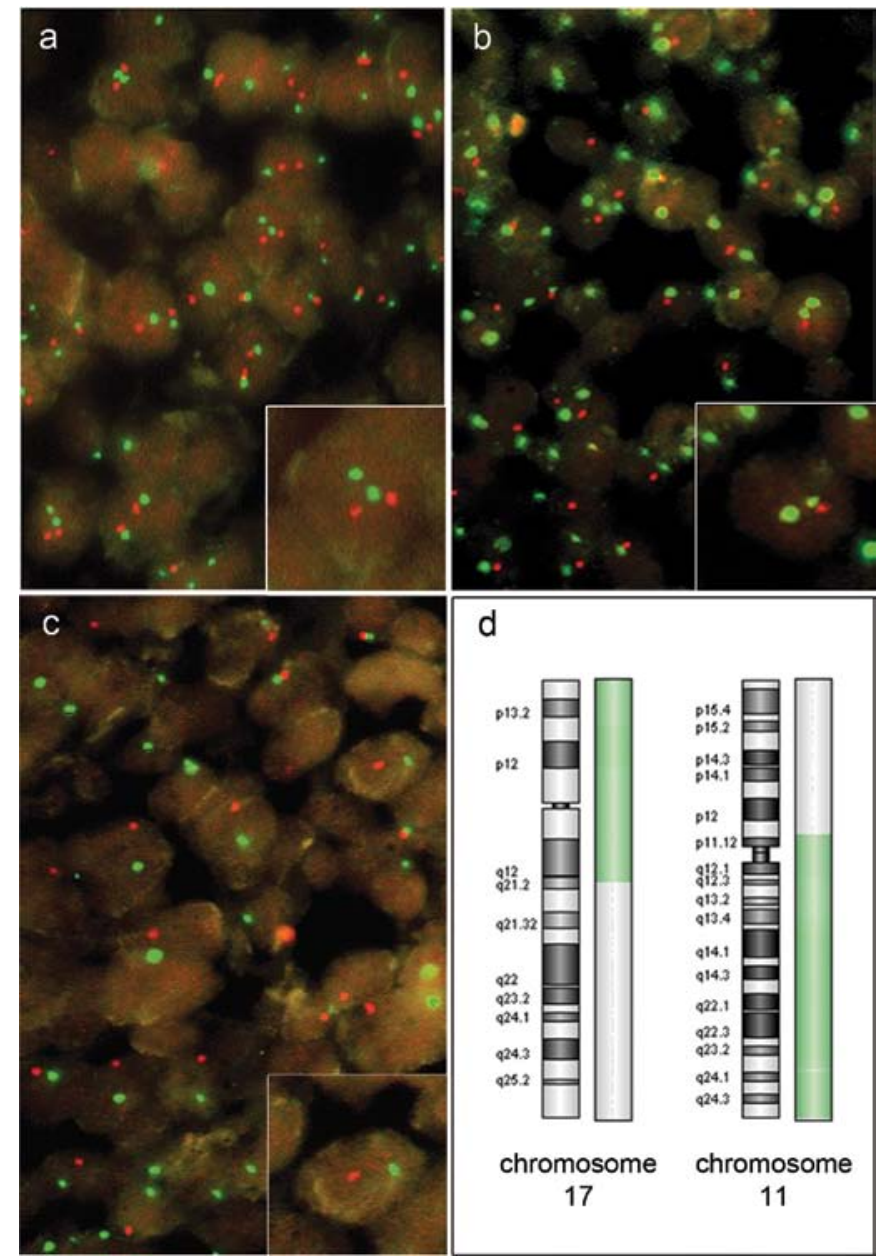

d
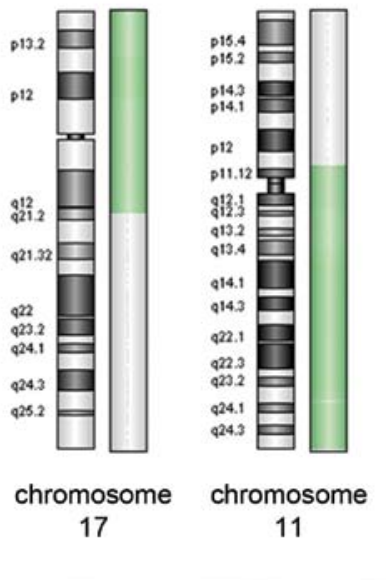

Figure 2. Detection of the $p 53$ and ATM deletion by FISH and array CGH. (a) nuclei negative for deletion of $p 53(2 \mathrm{R}+2 \mathrm{G})$; (b) nuclei positive for deletion of $p 53(2 \mathrm{G}+1 \mathrm{R})$; (c) nuclei positive for deletion of p53 (1G+1R); (d) schematic representation of array CGH in case 44, the parts of chromosomes highlighted in green were deleted.

the remaining $p 53$ allele was mutated. Deletion of ATM allele was also detected in 10 cases (Table III), whereas concurrent deletion of both p53 and ATM was found in 3 samples (cases $30,44,61)$.

Analysis of the p53 protein by immunoblotting. The level of p53 was assessed according to the control; human breast cancer cell line BT474. The BT474 cells bear $p 53$ mutation E285K and constitutively overexpress the p53 protein $(+++)$. We found 10 DLBCL cases with high level of the p53 protein (+++), 8 of them having the $p 53$ gene mutated. Six cases featured median level $(++)$ and 19 cases low level $(+)$ of the p53 protein, three of them had $p 53$ affected by missense mutation. In 40 cases, including 3 cases bearing p53 missense mutation, no p53 protein (-) was detected (Fig. 3).

The relationship between the p53 status and the disease outcome. We compared selected parameters separately in de novo DLBCL cases and in patients with transformed DLBCL. These two groups differed in some clinical parameters, such as disease stages $(\mathrm{p}<0.001)$, IPI AA categories $(\mathrm{p}=0.026)$, ECOG categories $(p=0.041)$, rate of complete remission $(p=0.01)$, e.g. as 


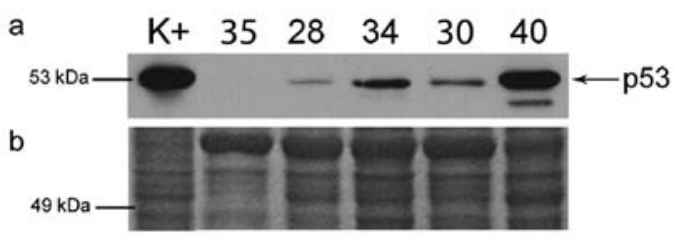

Figure 3. Assessment of the p53 protein level by immunoblotting using DO-1 antibody (a) and total protein fraction stained with coomassie brilliant blue (b). $\mathrm{K}^{+}$, positive control; human cell line BT474 bearing mutation E285K.

shown in Table I. The distribution of detected p53 aberrations between the two groups is summarized in Table III. Median overall survival (OS) for the whole cohort was not reached. Median progression-free survival (PFS) was 59.9 months. We did not find any statistically significant difference in survival (both OS and PFS) between de novo and transformed DLBCL groups of patients.

The overall survival of de novo DLBCL patients $(\mathrm{N}=54)$ was not affected by any p53 aberration ( $p 53$ mutation, p53 allele deletion, $p 53$ mutation and/or deletion, p53 protein overexpression). The presence of $p 53$ mutation and/or deletion decreased PFS in this group of patients but the result was on the border of statistical significance $(\mathrm{p}=0.051)$. However, the evaluated group of de novo DLBCL patients was heterogeneous in terms of applied therapy. Eight cases did not receive rituximab compared to 46 de novo DLBCL patients who were treated with R-CHOP therapy. All 12 cases with mutated $p 53$ were treated with $\mathrm{R}-\mathrm{CHOP}$, in 3 of them the mutation was accompanied by deletion of the second allele. In case 43 with deletion of $p 53$ allele the mutational status was not evaluated. Together there were 13 patients with mutation and/ or deletion of $p 53$ among cases treated with R-CHOP. The statistical analyses of survival in those 46 patients revealed a clear difference in OS as well as PFS in dependence on p53 mutation and/or deletion. For PFS the result was statistically significant $(\mathrm{p}=0.021), 72.1 \%$ of patients without any $p 53$ aberration and only $33.3 \%$ of patients with mutations and/or deletions of $p 53$ survived 24 months (Fig. 4).

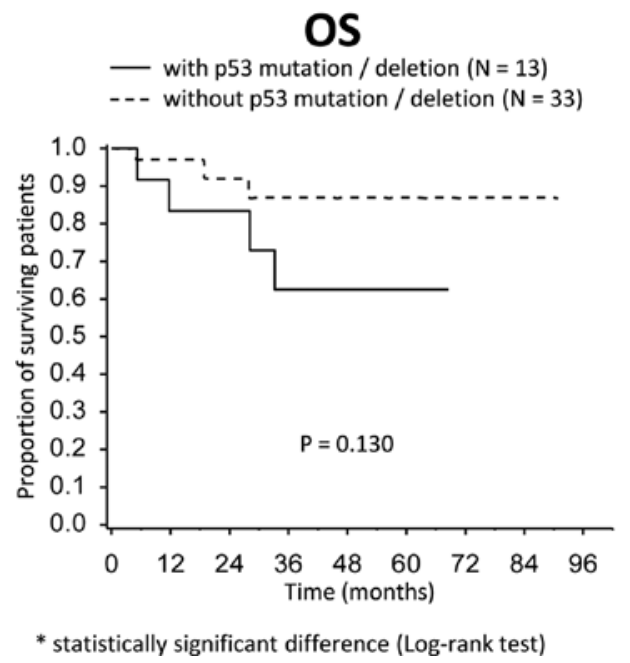

The group of 21 transformed DLBCL cases was too small to provide statistically significant results but the presence of p53 mutation and/or deletion also decreased OS as well as PFS of patients. Interestingly, de novo DLBCL patients with deletion of $A T M(\mathrm{~N}=6)$ exhibited better survival rate (both $\mathrm{OS}$ and PFS) compared to patients with both $A T M$ alleles $(\mathrm{N}=45)$. Due to low number of cases with loss of $A T M$, the results were not statistically significant.

\section{Discussion}

We detected mutation of the p53 gene in 16 (21.3\%) cases. Twelve of them were found in de novo DLBCL patients (22.2\%), four in transformed cases $(19.0 \%)$. The mutational rate in our study is in good agreement with other studies where the frequency of the $p 53$ mutations ranged mostly from 13 to $23 \%(23-25,27,28,50-53)$ as well as with multicentric study comprising 477 DLBCL patients, in which the mutational ratio was $21.4 \%$ (26).

In our previous study on mantle cell lymphomas, we identified deletion of the $p 53$ allele only in cases with mutated p53 and also the p53 protein overexpression was associated only with p53 mutations (48). In contrast, in this study patients lacking the $p 53$ mutation with loss of p53 allele and/ or $\mathrm{p} 53$ protein overexpression were found. The $\mathrm{p} 53$ protein was mainly accumulated in tissues containing mutant p53 $(80 \%$ of cases having high protein expression contained p53 mutation). High p53 protein level in cases with functional p53 was described also by Young et al (25) and Villuendas et al (54). These results suggest that besides the $p 53$ mutations there are other mechanisms leading to stabilization of p53 in DLBCL cancer cells and highlight necessity to analyze both mutational status of the $p 53$ gene and the p53 protein level.

The $p 53$ mutations were described to decline the rate of complete remission in DLBCL patients $(23,25)$. Several studies showed significant impact of the p53 mutations on OS of DLBCL patients $(23,25,26,28)$. However, there are other studies with contrary findings on adverse effect of the $p 53$ mutations on prognosis of NHL patients $(52,55)$. According

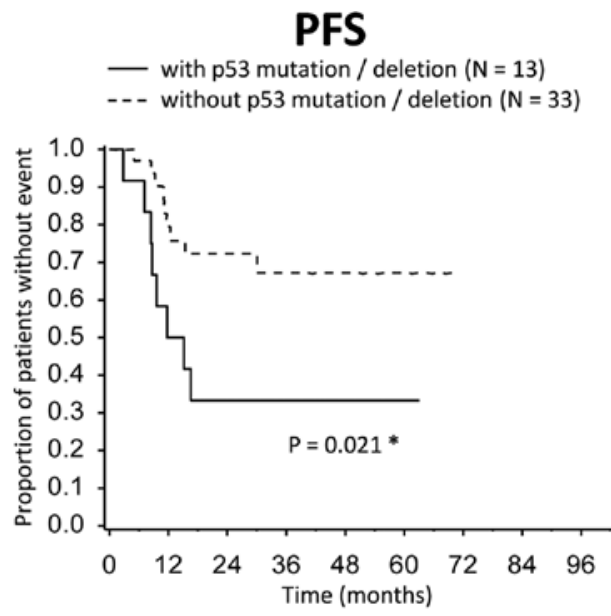

Figure 4. Overall survival (OS) and progression-free survival (PFS) of patients with de novo DLBCL treated with rituximab according to presence of $p 53$ mutation and/or $p 53$ deletion. 
to the collaborative study of Young et al (25), the $p 53$ deletion has no adverse impact on DLBCL patients survival while the level of mutant p53 protein negatively influences the survival rate of patients.

In our present study, we prove statistically significant adverse effect of the 553 aberrations on PFS of DLBCL patients treated with R-CHOP. The tendency of $p 53$ aberrations to decrease OS is also clearly shown. The main reason why the statistically significant level was not reach is probably the small number of patients in the study. Other studies analyzed larger groups of DLBCL patients [102 (23); 113 (25); 477 (26); 102 (27)]. We did not observe a negative effect of high p53 protein level on de novo DLBCL patient survival. Some samples accumulating p53 were not affected by $p 53$ mutation suggesting different mechanism responsible for the p53 protein stabilization. High level of functional p53 could provide different effect than high level of mutated p53.

The ATM gene is believed to play an important role in lymphomagenesis and the deletion of this locus was shown to correlate with lymphoma phenotype (39). Loss of the ATM allele was supposed as a second hit after mutation in the second allele (41). However, cases with deletion of one allele without any mutation also exist (40). We found ATM deletion in $13.9 \%$ of analyzed cases and in $11.1 \%$ of de novo group similarly to Cuneo et al (39). The $p 53$ and ATM mutations occur independently in MCL (41), while in DLBCL non-random coexistence of these alterations was found (37). Simultaneous inactivation of both p53 and ATM resulted in excellent prognosis in the study of Jiang et al (38). In our study, 7 cases with ATM deletion did not have any aberration of $p 53$. Three ATM deletion-positive cases had p53 deletion two of them carry p53 temperature-sensitive mutation in the second allele. Two of these patients (one with and one without p53 mutation) responded well to initial treatment and are in complete remission while the remaining case (44) transformed from follicular lymhoma and died 5 months later.

In conclusion, we performed complex analysis of the p53 aberrations in DLBCL. We used combination of several alternative methods to address the p53 function and showed that this complex approach provides valuable insight into the ways of the p53 impairment. Although the group of R-CHOP-treated DLBCL patients analyzed in this study was rather small, we showed that the $p 53$ aberrations retain adverse effect on their survival.

\section{Acknowledgements}

This work was supported by grants NR/9305-3 and NS/10448-3 of the Internal Grant Agency of the Ministry of Health of the Czech Republic, MSM0021622415 of the Ministry of Education, Youth and Sports of the Czech Republic, and 204/08/H054 of Grant Agency of Czech Republic.

\section{References}

1. Fisher RI, Gaynor ER, Dahlberg S, et al: Comparison of a standard regimen (CHOP) with three intensive chemotherapy regimens for advanced non-Hodgkin's lymphoma. N Engl J Med 328: 1002-1006, 1993.

2. Kramer MH, Hermans J, Wijburg E, et al: Clinical relevance of BCL2, BCL6, and MYC rearrangements in diffuse large B-cell lymphoma. Blood 92: 3152-3162, 1998.
3. Lossos IS, Okada CY, Tibshirani R, et al: Molecular analysis of immunoglobulin genes in diffuse large B-cell lymphomas. Blood 95: 1797-1803, 2000

4. Alizadeh AA, Eisen MB, Davis RE, et al: Distinct types of diffuse large B-cell lymphoma identified by gene expression profiling. Nature 403: 503-511, 2000.

5. Rosenwald A, Wright G, Chan WC, et al: The use of molecular profiling to predict survival after chemotherapy for diffuse largeB-cell lymphoma. N Engl J Med 346: 1937-1947, 2002.

6. Rosenwald A, Wright G, Leroy K, et al: Molecular diagnosis of primary mediastinal B cell lymphoma identifies a clinically favorable subgroup of diffuse large B cell lymphoma related to Hodgkin lymphoma. J Exp Med 198: 851-862, 2003.

7. Savage KJ, Monti S, Kutok JL, et al: The molecular signature of mediastinal large B-cell lymphoma differs from that of other diffuse large B-cell lymphomas and shares features with classical Hodgkin lymphoma. Blood 102: 3871-3879, 2003.

8. Staudt LM and Dave S: The biology of human lymphoid malignancies revealed by gene expression profiling. Adv Immunol 87: 163-208, 2005.

9. Hans CP, Weisenburger DD, Greiner TC, et al: Confirmation of the molecular classification of diffuse large B-cell lymphoma by immunohistochemistry using a tissue microarray. Blood 103: 275-282, 2004

10. Chang CC, McClintock S, Cleveland RP, et al: Immunohistochemical expression patterns of germinal center and activation B-cell markers correlate with prognosis in diffuse large B-cell lymphoma. Am J Surg Pathol 28: 464-470, 2004.

11. Muris JJ, Meijer CJ, Vos W, et al: Immunohistochemical profiling based on Bcl-2, CD10 and MUM1 expression improves risk stratification in patients with primary nodal diffuse large B cell lymphoma. J Pathol 208: 714-723, 2006.

12. Choi WW, Weisenburger DD, Greiner TC, et al: A new immunostain algorithm classifies diffuse large B-cell lymphoma into molecular subtypes with high accuracy. Clin Cancer Res 15: 5494-5502, 2009.

13. Lossos IS: Molecular pathogenesis of diffuse large B-cell lymphoma. J Clin Oncol 23: 6351-6357, 2005.

14. Nyman H, Adde M, Karjalainen-Lindsberg ML, et al: Prognostic impact of immunohistochemically defined germinal center phenotype in diffuse large B-cell lymphoma patients treated with immunochemotherapy. Blood 109: 4930-4935, 2007.

15. Smith MR: Rituximab (monoclonal anti-CD20 antibody): mechanisms of action and resistance. Oncogene 22: 7359-7368, 2003.

16. Coiffier B, Lepage E, Briere J, et al: CHOP chemotherapy plus rituximab compared with CHOP alone in elderly patients with diffuse large-B-cell lymphoma. N Engl J Med 346: 235-242, 2002.

17. Pfreundschuh M, Trümper L, Osterborg A, et al: CHOP-like chemotherapy plus rituximab versus CHOP-like chemotherapy alone in young patients with good-prognosis diffuse large-Bcell lymphoma: a randomised controlled trial by the MabThera International Trial (MInT) Group. Lancet Oncol 7: 379-391, 2006.

18. Bea S and Campo E: Secondary genomic alterations in nonHodgkin's lymphomas: tumor-specific profiles with impact on clinical behavior. Haematologica 93: 641-645, 2008.

19. Ye BH, Lista F, Le Coco F, et al: Alterations of a zinc fingerencoding gene, BCL-6, in diffuse large-cell lymphoma. Science 262: 747-750, 1993

20. Møller MB, Ino Y, Gerdes AM, Skjødt K, Louis DN and Pedersen NT: Aberrations of the p53 pathway components p53, MDM2 and CDKN2A appear independent in diffuse large B cell lymphoma. Leukemia 13: 453-459, 1999.

21. Winter JN, Weller EA, Horning SJ, et al: Prognostic significance of Bcl-6 protein expression in DLBCL treated with CHOP or R-CHOP: a prospective correlative study. Blood 107: 4207-4213, 2006.

22. Mounier N, Briere J, Gisselbrecht C, et al: Rituximab plus CHOP (R-CHOP) overcomes bcl-2--associated resistance to chemotherapy in elderly patients with diffuse large B-cell lymphoma (DLBCL). Blood 101: 4279-4284, 2003.

23. Ichikawa A, Kinoshita T, Watanabe T, et al: Mutations of the p53 gene as a prognostic factor in aggressive B-cell lymphoma. $\mathrm{N}$ Engl J Med 337: 529-534, 1997.

24. Møller MB, Gerdes AM, Skjødt K, Mortensen LS and Pedersen NT: Disrupted p53 function as predictor of treatment failure and poor prognosis in B- and T-cell non-Hodgkin's lymphoma. Clin Cancer Res 5: 1085-1091, 1999.

25. Young KH, Weisenburger DD, Dave BJ, et al: Mutations in the DNA-binding codons of TP53, which are associated with decreased expression of TRAILreceptor-2, predict for poor survival in diffuse large B-cell lymphoma. Blood 110: 4396-4405, 2007. 
26. Young KH, Leroy K, Møller MB, et al: Structural profiles of TP53 gene mutations predict clinical outcome in diffuse large B-cell lymphoma: an international collaborative study. Blood 112: 3088-3098, 2008.

27. Zainuddin N, Berglund M, Wanders A, et al: TP53 mutations predict for poor survival in de novo diffuse large B-cell lymphoma of germinal center subtype. Leuk Res 33: 60-66, 2009.

28. Leroy K, Haioun C, Lepage E, et al: p53 gene mutations are associated with poor survival in low and low-intermediate risk diffuse large B-cell lymphomas. Ann Oncol 13: 1108-1115, 2002.

29. Harris SL and Levine AJ: The p53 pathway: positive and negative feedback loops. Oncogene 24: 2899-2908, 2005.

30. Sherr CJ: Principles of tumor suppression. Cell 116: 235-246, 2004.

31. Lowe SW, Cepero E and Evan G: Intrinsic tumour suppression. Nature 432: 307-315, 2004.

32. Brosh R and Rotter V: When mutants gain new powers: news from the mutant p53 field. Nat Rev Cancer 9: 701-713, 2009.

33. Haupt Y, Maya R, Kazaz A and Oren M: Mdm2 promotes the rapid degradation of p53. Nature 387: 296-299, 1997.

34. Honda R, Tanaka H and Yasuda H: Oncoprotein MDM2 is a ubiquitin ligase E3 for tumor suppressor p53. FEBS Lett 420: 25-27, 1997.

35. Wu XW, Bayle JH, Olson D and Levine AJ: The p53 mdm-2 autoregulatory feedback loop. Genes Dev 7: 1126-1132, 1993

36. Rotman G and Shiloh Y: ATM: from gene to function. Hum Mol Genet 7: 1555-1563, 1998.

37. Grønbaek K, Worm J, Ralfkiaer E, Ahrenkiel V, Hokland P and Guldberg P: ATM mutations are associated with inactivation of the ARF-TP53 tumor suppressor pathway in diffuse large B-cell lymphoma. Blood 100: 1430-1437, 2002.

38. Jiang H, Reinhardt HC, Bartkova J, et al: The combined status of ATM and p53 link tumor development with therapeutic response. Genes Dev 23: 1895-1909, 2009.

39. Cuneo A, Bigoni R, Rigolin GM, et al: Acquired chromosome $11 \mathrm{q}$ deletion involving the ataxia teleangiectasia locus in B-cell non-Hodgkin's lymphoma: correlation with clinicobiologic features. J Clin Oncol 18: 2607-2614, 2000.

40. Greiner TC, Dasgupta C, Ho VV, et al: Mutation and genomic deletion status of ataxia telangiectasia mutated (ATM) and p53 confer specific gene expression profiles in mantle cell lymphoma. Proc Natl Acad Sci USA 103: 2352-2357, 2006.

41. Camacho E, Hernandez L, Hernandez S, et al: ATM gene inactivation in mantle cell lymphoma mainly occurs by truncating mutations and missense mutations involving the phosphatidylinositol-3 kinase domain and is associated with increasing numbers of chromosomal imbalances. Blood 99: 238-244, 2002.

42. Fang NY, Greiner TC, Weisenburger DD, et al: Oligonucleotide microarrays demonstrate the highest frequency of ATM mutations in the mantle cell subtype of lymphoma. Proc Natl Acad Sci USA 100: 5372-5377, 2003.
43. Flaman JM, Frebourg T, Moreau V, et al: A simple p53 functional assay for screening cell lines, blood, and tumors. Proc Natl Acad Sci USA 92: 3963-3967, 1995.

44. Smardova J, Nemajerova A, Trbusek M, Vagunda V and Kovarik J: Rare somatic p53 mutation identified in breast cancer: a case report. Tumor Biol 22: 59-66, 2001.

45. Ishioka C, Frebourg T, Yan YX, et al: Screening patients for heterozygous p53 mutations using a functional assay in yeast. Nat Genet 5: 124-129, 1993

46. Waridel F, Estreicher A, Bron L, et al: Field cancerisation and polyclonal p53 mutation in the upper aerodigestive tract. Oncogene 14: 163-169, 1997.

47. Silva AL and Romao L: The mammalian nonsense-mediated mRNA decay pathway: To decay or not to decay! Which players make the decision? FEBS Lett 583: 499-505, 2009.

48. Stefancikova L, Moulis M, Fabian P, et al: Loss of the p53 tumor suppressor activity is associated with negative prognosis of mantle cell lymphoma. Int J Oncol 36: 699-706, 2010.

49. Grochova D, Vankova J, Damborsky J, et al: Analysis of transactivation capability and conformation of p53 temperaturedependent mutants and their reactivation by amifostine in yeast. Oncogene 27: 1243-1252, 2008.

50. Koduru PR, Raju K, Vadmal V, et al: Correlation between mutation in P53, p53 expression, cytogenetics, histologic type, and survival in patients with B-cell non-Hodgkin's lymphoma. Blood 90: 4078-4091, 1997.

51. Sanchez-Beato M, Saez AI, Navas IC, et al: Overall survival in aggressive B-cell lymphomas is dependent on the accumulation of alterations in p53, p16, and p27. Am J Pathol 159: 205-213, 2001.

52. Barrans SL, Carter I, Owen RG, et al: Germinal center phenotype and bcl-2 expression combined with the International Prognostic Index improves patient risk stratification in diffuse large B-cell lymphoma. Blood 99: 1136-1143, 2002.

53. Mitani S, Kamata H, Fujiwara M, et al: Missense mutation with/ without nonsense mutation of the p53 gene is associated with large cell morphology in human malignant lymphoma. Pathol Int 57: 430-436, 2007.

54. Villuendas R, Piris MA, Algara P, et al: The expression of $\mathrm{p} 53$ protein in non-Hodgkin's lymphomas is not always dependent on p53 gene mutations. Blood 82: 3151-3156, 1993.

55. Osada M, Ishioka C, Ichinohasama R, et al: Influence of p53 mutation on pathological grade, but not prognosis of nonHodgkin's lymphoma. Anticancer Drug Des 14: 107-114, 1999. 